\title{
ESTRATEGIAS RETÓRICAS PARA LA ESCRITURA AUTOBIOGRÁFICA EN LA HISTORIA DE LAS INDIAS ${ }^{1}$ DE FRAY BARTOLOMÉ DE LAS CASAS
}

Marco Urdapilleta Muñoz*

\begin{abstract}
RESUMEN: Lo autobiográfico en la Historia de las Indias no debe ser comprendido como una muestra más de la incontrolable subjetividad del obispo de Chiapa porque la autoescritura estuvo regulada por la historiografía. En una historia diferente el dominico asumió un papel protagónico-ejemplar. La propia presentación siguió el modelo de la confesión y proyectó dos facetas de la actuación del obispo: el justo y la del elegido. Para acreditar su biografismo usó varios recursos como señalar sus atributos morales y crear un efecto de distancia entre narrador y personaje.
\end{abstract}

PALABRAS CLAVE: Bartolomé de Las Casas, Crónica de Indias, Autobiografía, Retórica.

ABSTRACT: The autobiography in the History of the Indias should not be understood as a sample more than the uncontrollable subjectivity of the Bishop of Chiapa. The self writing is justified is justified and regulated by historical institution. The self representation followed the pattern of confession and it projected two facets of the bishop's performance fundamentally: the fair one and that of elect. To credit their biographic intention he used several resources like to point out their moral attributes and to create a distance effect between narrator and character.

WORD KEYS: Bartolomé de las Casas, Chronicle of Indias, Autobiography, Rhetoric.

Hasta $1520,{ }^{2}$ año en el que fray Bartolomé de las Casas (Sevilla, 1484Madrid, 1566) fijó el límite de la tercera década de su Historia de las In-

\footnotetext{
*Facultad de Humanidades UAEM (marcoumx@yahoo.es).

${ }^{1} \mathrm{Al}$ citar la Historia de las Indias mantengo los signos de la edición crítica: entre corchetes se encuentran las palabras que se añadieron y los señalamientos acerca de incorrecciones léxicas del obispo. Mis intervenciones en el texto van marcadas con negritas.

${ }^{2}$ Pese a esta determinación temporal Las Casas narra acontecimientos que rebasan el tiempo fijado en la tercera década para dar cabida a sucesos en los que participó directamente.
} 
dias ${ }^{3}$ su presencia como actor en todas las historias generales contemporáneas — pienso en las Décadas de Anglería (1511-1525), en Historia general y natural de las Indias de Gonzalo Fernández de Oviedo (1535) y en la Historia general de las Indias y Vida de Hernán Cortés de Gómara (1552) - quedó reseñada únicamente por el episodio del fallido intento de colonización pacífica en Cumaná (1520-1521). En cambio, en su Historia de las Indias fray Bartolomé concedió a su vida un inusitado relieve. Una forma de comprensión de este prurito autobiográfico hizo hincapié en que la perceptible presencia del dominico constituye una muestra palpable de su "afán de protagonismo," pues al estar movido por su egolatría y/o otras pasiones, no dudó en pasar al primer plano del escenario histórico. Otra explicación semejante sugiere que la escritura autobiográfica es una consecuencia más de la incontrolable subjetividad de un historiador que toma partido y que de cualquier forma trata de defender su posición ideológica en el contexto de un debate político.

Si bien es posible pensar que es excesivo el espacio dedicado a lo autobiográfico, evidente incluso para el cronista oficial Antonio de Herrera y Tordesillas, que siguió prácticamente al pie de la letra en su Historia general de los hechos de los castellanos en las Islas y Tierra Firme del mar Océano la historia de Las Casas (en lo que concierne al avance español por el Caribe hasta 1520), resulta difícil compartir por completo estos puntos de vista en la medida en que carecen de ciertos matices explicativos importantes. Me parece necesario, entonces, demostrar que más allá de las pasiones protagónicas y de la mera exaltación atribulada del yo, la Historia de las Indias está condicionada por la institución histórica, como puede leerse con claridad en el prólogo de la obra. En esta mediación los cauces discursivos de la oratoria antigua y medieval en modo alguno resultaron ajenos al dominico, que muy bien sabía qué es lo que podía y debía ser expresado en un texto histórico, pese a digresio-

\footnotetext{
${ }^{3}$ Fray Bartolomé inició la Historia de las Indias en 1527 y la terminó en 1561 según lo estableció Isascio Pérez en el estudio preliminar a esta obra. El prólogo data de 1552; el primer libro o década fue escrito de 1527 a 1556, el segundo de 1558 a 1559 y el tercero de 1559 a 1561 .
} 
nes incomprensibles. En función de esta afirmación es factible sostener que el espacio autobiográfico no debe ser reducido al puro ripio ideológico ni al mero impulso de amplificación retórica o a la mera expresión de la egolatría; por el contrario, la presencia del personaje fray Bartolomé de las Casas desempeñó un papel pertinente, por su relevancia, en el desarrollo del acontecer histórico plasmado en la Historia de las Indias.

Para comprender el citado "afán de protagonismo" es preciso puntualizar las regulaciones discursivas que guiaron la autoescritura del dominico. En este sentido, primero se observa la forma en que fray Barolomé justifica la escritura autobiográfica en un texto histórico del siglo XVI; luego la pregunta es por la forma de encauzarla y, finalmente, por la imagen que proyecta de sí mismo.

Varias son las razones de la autoescritura lascasiana, legitimadas por las convenciones historiográficas del momento:

1) La vida de fray Bartolomé adquiere relieve en una historia distinta de carácter contestatario, "refutación" u "oposición". ${ }^{4}$ No hay duda, pues, de que la Historia de las Indias sustenta una interpretación del acontecer radicalmente diferente a la de la mayor parte de los cronistas de Indias, incluso opuesta. Vale traer rápidamente a modo de ejemplo, estas dos perspectivas con un párrafo. Por un lado la conocida y concluyente visión de Francisco López de Gómara. ${ }^{5}$

Si llegamos como espero en Dios nuestro señor, no sólo ganaremos para nuestro Emperador y rey natural rica tierra, grandes reinos, infinitos vasallos, sino también para nosotros mismos muchas riquezas, oro, plata, piedras,

\footnotetext{
${ }^{4}$ Victor Frankl en El antijovio de Gonzalo Jiménez de Quesada y las concepciones de realidad y verdad en la época de la contrarreforma y del manierismo, pról. de José Antonio Maravall, Madrid, Ediciones Cultura Hispánica, 1963, 523 pp., llamó "historia de oposición" o "historia de refutación" al texto histórico cuya intención fue "retener no sólo un trozo de realidad, sino también a refutar otra descripción de la misma realidad, y escrita, por consiguiente, no sólo en vista de la imagen del hecho en cuanto tal, sino con miras a otra interpretación del mismo, hasta tal punto, que toda la exposición histórica aparece orientada por la exposición del adversario."

${ }^{5}$ Francisco López de Gómara, Historia general de las Indias y vida de Hernán Cortés, pról. y cron. de Jorge Gurría Lacroix, Caracas, Biblioteca Ayacucho, 1979, 454 pp., p. 312.
} 
perlas y otros haberes; y aparte esto, la mayor honra y prez que hasta nuestros tiempos, no digo nuestra nación, sino ningún otra ganó; porque cuanto mayor rey es éste tras el que andamos, cuanto más ancha tierra, cuanto más enemigos, tanto es mayor nuestra gloria, $\mathrm{y}$, ¡no habéis oído decir que cuantos más moros más ganancias? Además de todo esto, estamos obligados a ensalzar y ensanchar nuestra santa fe católica, como comenzamos y como buenos cristianos, desarraigando la idolatría, blasfemia tan grande de nuestro Dios; quitando los sacrificios y comida de carne de hombres, tan contra natura y tan usada, y excusando otros pecados que por su torpedad no los nombro.

Por el otro, la también conocida del obispo de Chiapa: "Cierto, fueron hazañas tan grandes y tan señaladas que, después que Dios crió a Adán y permitió en el mundo pecados, otras tales ni tantas ni con tan execrables y creo que inexpiables ofensas de Dios ni fueron jamás hechas ni pudieron ser pensadas ni aun soñadas. ${ }^{6}$

Así, si esta historiografía cuenta la epopeya, la Historia de las Indias descubre la "destrucción", la "tiranía"; si ésta pregona la fama de la nación hispana y de sus guerreros victoriosos, el fraile sevillano sustenta que la "infamia" ha caído sobre España y hasta cierto punto sobre sus gobernantes, etc. En una historia como esta fray Bartolomé resulta no sólo un testigo sino, al mismo tiempo, un actor social relevante, incluso un gestor de la historia.

2) El carácter apologético de la autoescritura. La condición gestor de la "reformación de las Indias" hizo al obispo objeto de severos escrutinios por parte de sus adversarios y consideró que debía defenderse de la mala fe y la incomprensión de la cual fue un frecuente blanco. Entonces, directa y legítimamente habló de su vida para exponer su punto de vista y enfrentar lo que consideraba como versiones que le restaban fiabilidad como actor político en la medida en que lo dejaban mal parado como

${ }^{6}$ Bartolomé de las Casas, Historia de las Indias, 3 vols., transcripción de Miguel Ángel Medina; fijación de fuentes, Jesús Ángel Barreda; estudio y análisis crítico, Isascio Pérez Fernández, en Obras completas, 14 vols., edición preparada por la fundación "Instituto Bartolomé de las Casas" de los dominicos de Andalucía bajo la dirección de Paulino Castañeda Delgado, Madrid, Alianza/ Junta de Andalucía, 2716 pp., p. 1526. 
persona digna de crédito o como se expresa en las Siete partidas (Partida 3 tit. 18, ley 1) 7 “persona auténtica." Este marco aclaratorio fue necesario, dice Las Casas, "porque según los juristas, las corónicas — mayormente las antiguas - hacen probanza o, al menos, adminículo de prueba en juicio". ${ }^{8}$ Las Casas hizo, pues, énfasis en la necesidad jurídica de fincar su testimonio acerca de su vida y actuación. Aunque, como lo advirtieron algunos de sus biógrafos (Ángel Losada ${ }^{9}$ y Pedro Borges ${ }^{10}$ ) y estudiosos de su autoescritura (Santa $\operatorname{Arias}^{11}$ y María Teresa Silva ${ }^{12}$ ), esta legítima apología con frecuencia estuvo encaminada a mitigar sus errores así como a magnificar sus aciertos, procedimiento, por cierto, nada extraño a la defensa de cualquier tesis o persona.

3) La restauración de su buen nombre fue también una manera de obtener el reconocimiento propio de la historiografía pues la historia podía ser "premio y encomio" como lo expresa Fuentes y Guzmán, ${ }^{13}$ o bien, la fama. Ésta pone de manifiesto ante el público el honor personal, tal como se encuentra expresado en el código alfonsí: "buen estado del hombre que vive derechamente según ley y buenas costumbres, no teniendo en sí mancilla ni maldad". ${ }^{14}$ De ahí que pueda decirse que la intención apologética de Las Casas queda articulada y justificada como una defensa de su honor mancillado por lo que él considera la mentira, como se expresa en estos párrafos. ${ }^{15}$

${ }^{7}$ Alfonso X, Las siete partidas, Salamanca, Universidad de Salamanca, 1969, 839 pp.

${ }^{8}$ Las Casas, op.cit., p. 334.

${ }^{9}$ Ángel Losada, Fray Bartolomé de las Casas a la luz de la moderna crítica histórica, Madrid, Tecnos, 1970, 279 pp.

${ }^{10}$ Pedro Borges, ¿Quién era Bartolomé de las Casas?, Madrid, Rialp, 269 pp.

${ }^{11}$ Santa Arias, Retórica e ideología en la Historia de las Indias de Bartolomé de las Casas, UMI Disertation Services, 1990, 207 pp. (Tesis doctoral de la Facultad de Filosofía de la Universidad de Winsconsin).

${ }^{12}$ María Teresa Silva, "Las Casas, biógrafo de sí mismo”, en Historia de México, vol. 4, núm. 4, México, Colmex, 1955, pp. 34-60.

${ }^{13}$ Francisco Antonio Fuentes y Guzmán, Preceptos historiales, ed. y pról. de Ernesto Chinchilla Aguilar, Guatemala, Instituto de Antropología e Historia de Guatemala, 1957, 89 pp., p. 49.

${ }^{14}$ Las siete partidas, partida 7, tit. 6, ley 1.

${ }^{15}$ Las Casas, op. cit., p. 2468. 
Y aunque Oviedo excedió en hablar tan falsamente del clérigo, atribuyendo el deseo y fin que tuvo de mamparar [sic] estas desmamparadas gentes [sic] y quitar de su conversión y salvación tan eficaces impedimentos, a ambición y deseo de mandar, y también la cudicia [sic], todavía se sobrepujó en maldecir, detrayendo de la honra del clérigo Bartolomé de Las Casas.

Y con mayor desvergüenza el Francisco López de Gómara, capellán de Hernando de Cortés, porque dixo todo lo que Oviedo - porque de su libro lo tomó- y añidió [sic] cosas harto indecentes. ${ }^{16}$

5) Una vez que quedó justificada la presencia protagónica del obispo en una historia de nuevo cuño — es factible suponer el carácter ejemplar, crítico - edificante, que asume su vida. En esta historia el héroe a "imitar," poseedor de la virtud y, por consiguiente, del buen nombre, no es ya quien conquista, quien vence a los pueblos "servidores del Demonio", sino quien lucha por los derechos de estas naciones "tiranizadas"“salteadas" y "opresas" por los españoles. ${ }^{17}$ Es importante reconocer que tras

${ }^{16}$ Al referirse a los "excesos" de López de Gómara, tal vez Las Casas aludiera a la afirmación de que éste tenía la intención de mandar perlas a los potentados flamencos de la corte de Carlos I y que Gonzalo de Ocampo se burlaba del proyecto de colonización pacífica. En los demás aspectos centrales, Gómara siguió a Gonzalo Fernández de Oviedo (Historia general y natural de las Indias, edición y estudio de Juan Pérez de Tudela Bueso, 5 vols., Madrid, Atlas, 1958-1959, Biblioteca de Autores Españoles, vol. III, 459 pp., pp. 99-205). En resumen, estos cronistas advirtieron que fray Bartolomé se propuso un proyecto irrealizable - incluso ridículo - que costó mucho dinero y vidas españolas. La refutación de Las Casas se centró en mostrar que el proyecto era viable, haciendo constar mediante la exposición de los hechos que una parte de este fracaso fue debido a los mismos colonos. Las Casas acepta la pérdida de los recursos reales y las vidas, pero no como lo señala Oviedo que sumando las muertes en regiones cercanas en el lapso de un mes habla de cien. Gómara, por su parte, señaló que murieron todos los caballeros de "espuelas doradas." Las Casas sostuvo que perdieron la vida tres legos y un religioso. Los documentos que ahora han aparecido le dan por completo la razón al obispo.

${ }^{17}$ Lo ejemplar constituye un criterio que define la selección de los acontecimientos historiables. Según esto, el historiador debe comprender la relevancia, la cualidad sustancial de los hechos históricos con base en la estructura objetiva sustancial. Y lo sustancial en la perspectiva ejemplar remite a los elementos duraderos de la naturaleza humana. En este sentido, la historia no es la totalidad empírica de un acontecimiento, sino lo importante moralmente hablando. De ahí que la historia no hubiera constituido una disciplina autónoma, sino un saber adscrito a la moral en cuanto proporcionaba el material (ejemplos) para demostrar en el plano concreto y vital los enunciados teóricos abstractos. 
los exempla subyace la idea de una acumulación de "experiencia" (la historia, sentencia Cicerón es la "maestra de la vida" "luz de los tiempos", "espejo de la virtud" "tesoro de la prudencia"); pero, ante todo esta "experiencia" se tradujo en "lecciones de prudencia para el gobernante." ${ }^{18}$ De ahí que la Historia de las Indias tienda a lo político, incluso a la propaganda, pues, siguiendo las permisiones - propias de todo texto histórico de aquel tiempo-, persigue un fin político que en su caso es la reforma de Indias (supresión de las conquistas y encomiendas, y restitución de los frutos obtenidos de éstas).

Una vez que se ubicaron los motivos permitidos por la institución histórica para la autoescritura en la Historia de las Indias, surge otra cuestión que Las Casas comprendió bastante bien: cómo restar fuerza a los efectos de subjetividad y parcialidad propios de la autoescritura sin que disminuya el valor de su testimonio presencial. El asunto es delicado, primero, debido a que el campo autobiográfico tiene lugar en el marco de un texto histórico y, segundo, porque la Historia de las Indias se mantiene en un plano de impugnación que la retórica denomina "causa difícil" (causa anceps o dubia), esto es que en conjunto su perspectiva contradice en parte la "opinión general" ${ }^{19}$ con el propósito de rectificar la "verdad" de la narración histórica, pero sobre todo, la historia misma. Fray Bartolomé, entonces, intentó disminuir las marcas de esta subjetividad siguiendo dos vertientes: una consistió en presentar

${ }^{18}$ Luis Cabrera de Córdoba, De la historia. Para entenderla y escribirla, edición, estudio preliminar y notas de Santiago Montero Díaz, Madrid, Instituto de Estudios Políticos, 1948, 279 pp., p. 76.

${ }^{19}$ El grado de defendibilidad de una causa se mide por el contenido de la misma y su valoración ante el público o por el grado de simpatía que suscita ante los jueces $c f r$. Quintiliano [Marco Fabio], Institución oratoria, trad. de Ignacio Rodríguez y Pedro Sandier, pról. de Roberto Heredia, México, Conaculta, 1999 (Cien del Mundo), 630 pp., $4,1,4$. Por su parte, la "causa difícil" genera, en la conciencia general de los valores y la verdad del público, un serio problema acerca su defendibilidad. Cfr. Heinrich Lausberg, Manual de retórica literaria. Fundamentos de una ciencia literaria, 3 vols., $2^{\mathrm{a}}$ ed., trad. de José Pérez Riesco, Madrid, Gredos, 1975 (Biblioteca Románica Hispánica), vol. I, 423 pp., p. 113. 
una imagen autorizada de sí como historiador "desapasionado", esto es, "prudente", "honrado", "temeroso de Dios", de "no ancha conciencia."20 Tal imagen la construyó de diversas maneras: a) evidenciando y ponderando su "larga experiencia" en Indias que lo facultaba como poseedor de una aguda capacidad para comprender las motivaciones de los actores y circunstancias "soy el más viejo de edad que más ha vivido quizá y de más tiempo gastado por experiencia que hoy vive, si por ventura no hay uno o dos en todas estas occidentales Indias", ${ }^{21}$ b) enfatizando su condición de sacerdote, figura que traduce una firme moral: "Tampoco conviene a todo género de personas ocuparse con tal exercicio, según sentencia de Metástenes, sino a varones escogidos, doctos, prudentes, filósofos, perspicacísimos, espirituales y dedicados al culto divino, como entonces eran y hoy son los sabios sacerdotes", 22 c) manifestando que es un religioso "letrado" y por esto capaz de sobrepasar "la estéril superficie" ${ }^{23}$ del suceso histórico y entenderlos a la luz de la "recta razón". ${ }^{24}$

Veo algunos haber en cosas destas Indias escripto [sic], ya que no las vieron sino las que no bien oyeron (aunque no se jatan [sic] ellos así dello), y que con harto perjuicio de la verdad escriben, ocupados en la sequedad estéril e infructuosa de la superficie, sin penetrar lo que a al razón del hombre - a la cual todo se ha de ordenar- nutriría y edificaría; los cuales gastan su tiempo en relatar lo que sólo ceba de aire los oídos y ocupa la noticia y que cuantos más fuesen tanto menor daño al espíritu de los leyentes harían. ${ }^{25}$

${ }^{20}$ Las Casas, op. cit., p. 331.

${ }^{21}$ Ibid., p. 349.

22 Ibid., p. 331.

${ }^{23}$ Esto se debe a que en una concepción de la historia signada por el providencialismo el historiador debe inscribir el quehacer humano en el orden de lo sobrenatural. Esto es, la historia ve en la realidad sobrenatural la última fuente y clave de la comprensión del acontecer. O, dicho con otras palabras, "como notoriedad de los actos de Dios en la Historia y como esencial orientación de los actos humanos en pro o en contra de la obra de Dios" afirma Victor Frankl, op. cit., p. 237.

${ }^{24}$ De ahí que el testigo-historiador, dice el obispo deba ser un letrado, alguien que con buen ejercicio de la razón alcance la verdad, pues ésta no se localiza mediante la simple aprehensión del objeto a través de los sentidos.

${ }^{25}$ Las Casas, op. cit., pp. 337-338. 
d) Llamando la atención acerca de su nula preocupación por su beneficio personal y su gran afán por los asuntos religiosos:

Que ni tampoco por la segunda, desto asigno algunas conjecturas [sic]. Una sea que soy cristiano, y con esto religioso, y viejo de algunos más de sesenta años, y también, aunque no por los propios méritos, puesto en el número de los obispos. Las cuales calidades, consideradas por él (a quien la bondad divina conservó agora en su libre, natural, entero juicio), [sic] expender su tiempo y la breve vida que le resta por agradar a los hombres. ${ }^{26}$

e) También acredita Las Casas su testimonio enfatizando su condición de testigo privilegiado; puede verse su papel protagónico en un cúmulo de situaciones de gran importancia para el desarrollo del acontecer en Indias. Este protagonismo - en muchos aspectos justificado por completo - ocupa buena parte del tercer volumen de la Historia de las Indias. Sirva de ejemplo su destacada presencia en el Consejo Real de Castilla, el lugar desde donde se decide la política indiana, con el propósito de denunciar y gestionar proyectos de colonización pacífica.

Todo esto hace patente que en una cultura donde los procedimientos científicos no predominan, el criterio de la calidad y posición de la persona será esencial para calificar un texto como verdadero o "auténtico". ${ }^{27}$

the question, in a culture whose scientific procedures were so bound by the appeal to auctoritates, was how to make the text once created, authoritative. The answer was an appeal not to other texts (for there were non), nor to internal coherence, the logic of argument, the structure of the analogy, and so on, but to the authorial voice. It is "I" who has seen what no other being has seen alone is capable of giving credibility to the text. If the reader chooses be belive what he or she reads, is because he or she is willing to privilege that writer's claims to authority over all others and not, in this case, because it might seem to the reader to be inherently plausible or internaly consistent. ${ }^{28}$

${ }^{26}$ Ibid., p. 335.

${ }^{27}$ Los relatos, los libros, las crónicas, incluso los autores, pudieron ser calificados como "auténticos" afirma Bernard Guéene, Histoire et culture historique dans l' Occident médiéval, París, Aubier-Montaigne, 1980, 524 pp., p.133.

${ }^{28}$ Anthony Pagden, "Lus et factum: Text and Experience in the Writings of Bartolomé 
En la segunda vertiente fray Bartolomé escenificó una estrategia de distancia entre el personaje histórico y el historiador al contar su vida pasada en tercera persona (se refería a sí mismo como "el clérigo" o "el padre), pero este desdoblamiento del Yo no pretendía engañar al "prudente lector"; es una fórmula retórica de humildad, muy necesaria para la estrategia ejemplar del obispo, puesto que sin la autoescritura parece acercarse peligrosamente a la autoexaltación. La historia permitía la exaltación de las personas más encumbradas por su posición social o bien desde una perspectiva de la historia eclesiástica, la exaltación si puede decirse así "moderada" de las personas que dan muestras de virtudes cristianas. En efecto, no hay que perder de vista que la alabanza (laus), uno de los officia del género demostrativo o epidíctico - el propio del discurso ejemplar - califica lo honesto (honestum), la virtud y esta función epidíctica es deseable en la historia. Asimismo, tal desdoblamiento del Yo evidentemente alcanza a regular la información que el historiador quiere transmitir al controlar el grado de participación de su otro Yo (personaje) en los acontecimientos. Esto es, establece una pertinente distinción entre un historiador-testigo y un personaje narrado: "el clérigo", "micer Bartolomé" o "el clérigo Casas". El historiador de esta forma guarda una aparente distancia y con ello intenta acreditar su posición como testigo de vista privilegiado. Pero, por supuesto, el lector sabe de esta duplicidad y, sin duda alguna, identifica la voz de la tercera persona del historiador como la del mismo fray Bartolomé historiado.

En esta línea de la consecución de la objetividad, la selección de las palabras resulta también relevante. Por ejemplo, al tratar de la elección providencial del clérigo, el historiador se cuida de no manifestar directamente este designio para evitar un efecto de "soberbia". De ahí que el historiador modalice la condición de elegido del clérigo con el verbo "parecer": "parecía que debía [de] ser su propósito de ir a procurar el

de las Casas", Representations, núm. 33, California, University of California Press, 1995, 142-189 pp., pp. 150-151. 
remedio destas gentes divinalmente ordenado"; 29 o bien, "el clérigo por quien parecía que Dios peleaba." 30 Aunque no siempre es así: "Siente [el clérigo] que no puede ser industria humana" la forma en que obtiene sus propósitos. ${ }^{31}$ En cambio, en boca de los otros personajes históricos este "parece" ya no es frecuente.

También en este afán de objetividad hay otro foco de tensión porque la presencia del clérigo Bartolomé en tanto testigo-actor, fortalece directamente la acreditación del historiador, pues es "testigo de vista" y "sacerdote", ambos criterios sólidos para sustentar la "verdad", que en muchos aspectos aún no estaba fijada cabalmente a causa de la novedad de la materia indiana y de la disputa política.

En este espacio de contradicción y tensiones ¿cuál es la autoimagen que proyecta el obispo de Chiapa y que justifica intrínsecamente su autobiografismo? Para responder a esta pregunta es necesario ir primero a los aspectos formales que codifican la autoescritura. Como se dijo, la autoescritura de fray Bartolomé se condujo por las estrategias ejemplares propias de la historia, pero hizo un recorte importante al narrar su vida cuando eligió como pauta o modelo de escritura a la confesión. ${ }^{32}$ El núcleo estructurante de este género radica justamente en el acto de conversión. En términos generales, como género, la confesión es una narración en la que el confeso, desde un presente en el que adquiere una perspectiva nueva y verdadera de su vida luego de haberse convertido, reflexiona sobre su vida anterior, que en el momento actual le parece errada y contradictoria:

Al concepto de conversión solemos unir la imagen de una profunda y tajante cesura de la vida. Un hombre se encuentra con una idea y se deja dominar por su verdad; bajo el influjo de esta idea, liquida toda su vida anterior con

${ }^{29}$ Las Casas, op. cit., p. 2087.

${ }^{30}$ Ibid., p. 1227.

${ }^{31}$ Ibid., p. 2360.

${ }^{32}$ El modelo que siguieron los historiadores del siglos XVI para referir su vida fue el hagiográfico o el de las vidas ilustres, en Arias, op. cit., pp. 147-148. 
sus experiencias, conocimientos, modos de proceder [...] Con la conversión se le ha revelado una nueva dimensión de su destino; $y$, de esta manera, se produce un cambio total en la valoración de los hombres, de las cosas, de los acontecimientos. El converso es como un ciego al que, de pronto, insospechadamente, se concede la dicha de ver. ${ }^{33}$

Importa resaltar que la conversión desde el punto de vista cristiano significa, ante todo, el retorno a Dios luego de una vida licenciosa. Entonces, la narración ejemplar de la vida de fray Bartolomé, de acuerdo con el género que inició San Agustín, ${ }^{34}$ requirió de la presentación de elementos autobiográficos, léase "vivencias personales" significativas que muestren ese acto de retorno a Dios.

De acuerdo con esta situación, el periplo de fray Bartolomé va de un estado en el que vive en pecado alejado de Dios hasta otro en el que, ya convertido, sufre las pruebas que dan fe de la solidez de su conversión. Primero se muestra como un clérigo encomendero que "andaba bien ocupado y muy solícito en sus granjerías" — como los otros— 35 con "aparejo para ser rico" muy pronto ${ }^{36}$ y con una incipiente fama de "cudicioso" pues recibió una buena encomienda de indios por haber participado como capellán en la conquista de Cuba (1512-1514). Sin embargo, pondera su diferencia con respecto a los demás: él era un encomendero "bueno" porque procuraba "mantener [a los indios] cuanto le era posible y a tractallos [sic] blandamente y a compadecerse de sus miserias"; pero, siendo clérigo, "ningún cuidado tuvo más que los otros de acordarse de que eran hombres y de la obligación de dalles doctrina, y traellos al gremio de la Iglesia de Cristo." ${ }^{37}$ Así Pedro de Rentería con

${ }^{33}$ Baden H, Jürgen, Literatura y conversión, trad. de Juan González, Madrid, Guadarrama, 1969 , p. 9.

${ }^{34}$ Las Confesiones, de San Agustín, constituyen el paradigma formal según lo afirma William, Spengeman, The forms of Autobiography; Episodes in the History of a literary Genre, Londres, Yale University Press, New Haven, 1980, 289 pp., pp. 11-45.

${ }^{35}$ Las Casas op. cit., p. 2081.

${ }^{36}$ Ibid., p. 2081.

${ }^{37}$ Ibid., p. 2083. 
quien compartía su encomienda parecía ser más religioso que él, que aparecía como un mercader. Es importante notar que la imagen de hombre "bueno pero ciego" debió haber sido precedida por la de un conquistador que participó en las sangrientas guerras de Jaraguá (1503), Haniguayagua (1504) y la segunda campaña de Higüey (1504-1505), que con tanta fuerza logró describir. Esta suposición se sustenta en la idea de que no existen pistas que indiquen que su formación hubiera sido diferente a la de los demás colonos, ${ }^{38}$ pues incluso su mismo padre tenía encomienda y su misma opción religiosa con la que puso fin al guerrero (se ordenó en diciembre de 1506), no obedeció a un deseo de convertir a los paganos, sino a la de obtener beneficios. ${ }^{39}$ Esta omisión más que una llana mentira con probabilidad se debió a que su autoimagen ejemplar pudo sufrir algún menoscabo, pues como dominico y obispo dimisionario no podía dar lugar al "escándalo". Esta omisión puede ser un silencio, pero también un blanco lleno de sentido que corresponde al lector encontrarlo. ${ }^{40}$

Ahora, la conversión del clérigo apuntala una nueva imagen: la del caballero cristiano, "bueno," "virtuoso" que dejó ya las "tinieblas de la ignorancia", la "ceguedad" y la "insensibilidad". Pero su conversión no fue ningún "Camino de Damasco" pues más bien obedeció a una intensa reflexión de meses (en el texto dice "días"), motivada directamente por una derrota en una disputa/confesión con un sacerdote dominico anónimo y cuyo desenlace fue la idea de que era "injusto y tiránico todo

\footnotetext{
${ }^{38}$ No existen documentos que prueben que Las Casas haya estudiado Derecho en Sevilla y menos en Salamanca antes de desembarcar en América. Existen algunas pistas que han llevado a suponer que probablemente haya estudiado leyes en Valladolid hacia 1520 como lo aseveran Helen Rand y Harold Weidman, Las Casas en México. Historia y obras desconocidas, México, FCE, 459 pp., nota i y nota 90 de la primera parte.

${ }^{39} \mathrm{Cfr}$. Juan Pérez de Tudela y Bueso, "Significado histórico de la vida y escritos del padre Las Casas", en Prólogo a la Apologética historia sumaria, Madrid, Atlas, 1957, 701 pp., Biblioteca de Autores Españoles, p. CII; Isascio Pérez F., Cronología documentada de los viajes, estancias y actuaciones de fray Bartolomé de las Casas, San Juan de Puerto Rico, Centro de Estudios de los Dominicos del Caribe, Universidad Central de Bayamón, 1984, 829 pp., p. 147; Borges, op. cit., p. 42.

${ }^{40} \mathrm{Cfr}$. Béatrice Didier, "Les Blancs de l'autobiographie“, en Richard, Jean Pierre, Territoires de l'imaginaire, París, Du Seuil, 1986, 239 pp.
} 
cuanto cerca de los indios en estas Indias se cometía"; 41 pero sobre todo descubrió que era "una ofensa a Dios" pues como lo leyó en el Eclesiástico (34,18-22, en la traducción de la Biblia de Jerusalén), Dios no quiere ser honrado por quienes roban y matan:

Sacrificar cosa injusta es hacer ofrenda rechazada, no logran complacencia los presentes de los sin ley. No se complace el Altísimo en ofrendas de impíos, ni por el cúmulo de impíos, ni por el cúmulo de víctimas perdona los pecados. Inmola a un hijo a los ojos de su padre quien ofrece víctima a costa de los humildes. Pan de indigentes es la vida de los pobres, quien se lo quita es un hombre sanguinario. Mata a su prójimo quien le arrebata el sustento, vierte sangre quien quita el jornal al jornalero. ${ }^{42}$

Esto significa que Dios ha permitido ver a Las Casas su pecado así como el error en que estaban sus contemporáneos al poner en práctica un política de sojuzgamiento de los indios. Dejó, pues, la "ceguera". ${ }^{43}$ Esta actitud, como puede advertirse es típica del converso porque

La realidad se ve notablemente ampliada por la fe pero no porque la ahondemos ideológicamente, o proyectemos sobre su limitada superficie nuevos cuadros e imágenes, sino porque automáticamente sobrepasamos esas fronteras. La fe crea una nueva óptica, por medio de la cual podemos reconocer por primera vez verazmente la realidad: penetramos en sus fundamentos y honduras, en sus capas y galerías subterráneas, que escapan a la luz de la razón $[\ldots] .{ }^{44}$

Así, el clérigo, arrepentido de su "ceguedad", con su "alma en peligro" y la conciencia culpable, comprendió que su bondad era sólo un acto de racionalidad productiva y que su prédica y bautizos ocultaban la efectiva "preposteración” del fin de la presencia hispana en Indias, la evangeli-

${ }^{41}$ Las Casas, op. cit., p. 2082.

42 Ibid., p. 2081.

43 "It was God's word wich, in caracteristically Agustinian terms, has restored though grace the eye's capacity to see" afirma William Spengeman, op. cit., p. 60.

${ }^{44}$ Jürgen Baden, op. cit., p. 21. 
zación. Entonces pasó a la acción. Su primer acto fue dejar vacante su encomienda para poder predicar "libremente" la injusticia de la colonización. Es una forma de coherencia y por consiguiente legitimación pues luego de la renuncia a su encomienda, Velásquez, el gobernador de Cuba, sorprendido ante "cosa tan nueva y como monstruosa":

tuvo en muncha [sic] mayor reverencia al dicho clérigo; $y$, cerca de la gobernación, en lo que tocaba a los indios y aun en lo del regimiento de su misma persona, hacía muchas cosas buenas por el crédito que cobró dél, como si le hobiera [sic] visto hacer milagros. Y todos los demás de la isla comenzaron a tener en otro nuevo concepto dél que tenían de entonces y siempre lo ha sido estimado por el sumo argumento que de sanctidad [sic] podía mostrarse; tanta era y es la ceguedad de los que han venido a estas partes. ${ }^{45}$

Luego aparece como hombre decidido, de confianza para los dominicos y va a España, junto con Antón de Montesinos, para vencer la contumaz resistencia de los colonos. Ahí los religiosos informan y solicitan el "remedio."

Más allá del acontecer histórico, se va comprobando que poco a poco destaca en la conversión del clérigo la situación de su condición de elegido por la providencia. El lector, ya en el interior de la conciencia del personaje, asiste al reconocimiento de su vocación y su predestinación para llevar a cabo "El "propósito que Dios le había inspirado,"46 esto es, la salvación tanto de los indios como de los españoles. Sin embargo, la historia no termina ahí: el dramatismo de la narración se acentúa por el hecho de que pese a que es un elegido dotado por la providencia de "celo", "deseo" y "perseverancia"47 necesarios para lograr su propósito, se enfrenta siempre a la dificultad de comprender la voluntad divina porque estaba "en las cosas del mundo azolvado". Entonces, la lucha del clérigo en la corte es vista como un proceso de penitencia (en el sentido

\footnotetext{
${ }^{45}$ Las Casas, op. cit., pp. 2084-2085.

${ }^{46}$ Ibid., p. 2104.

${ }^{47}$ Ibid., p. 2100.
} 
de metanoia, de cambio) mediante el cual el converso profundiza su relación con Dios y fortalece su fe al ir adquiriendo una mayor espiritualidad. Los obstáculos los comprende Las Casas como prueba, y los fracasos quedan como indicio de que Dios no quiso "servirse de él" de la manera en que había actuado, tal como concluye el clérigo al tratar de comprender su fallido conato de evangelización pacífica en Cumaná en 1521, que finalizó con la muerte de un franciscano y otros 4 españoles. ${ }^{48}$ Considera más bien que en lugar de seguir la voluntad divina ofendió a Dios: "Y parece que ofendió a Dios maculando la puridad de su negocio espiritualísimo y fin que por sólo Dios pretendía [...] con la basura e impuridad terrenísima de medios tan humanos y aún inhumanos y tan desproporcionados de los que llevó Jesucristo." 49 Concretamente comprendió que el caballero cristiano descrito mediante la figura del clérigo-colono no era sino una "purificación”, como dice Marcel Batai1lon, ${ }^{50}$ de la figura del "encomendero."

En este estado de abatimiento, de "amargura", el clérigo llegó a la denominada "segunda conversión” — que es la única que explícitamente llamó de esa manera. Fue fray Domingo de Betanzos quien le dejó en claro que "parecía que no quería Dios servir del por aquel camino" (es decir, la búsqueda del beneficio material y la prédica del Evangelio. Y reflexiona, en términos generales, pero pensando en Colón ${ }^{51}$ en estos términos:

\footnotetext{
${ }^{48}$ Aunque también hay otra manera de comprender las adversidades de los elegidos de la providencia: "Las cosas grandes y de que Dios tiene muncha [sic] estima, como son las que han de resultar en honra y gloria suya y en provecho universal de su Iglesia y finalmente para bien y conclusión del número de sus predestinados, apenas se alcanzan [...] sino con innumerables dificultades, contradicciones, trabajos y peligros, ordenándolos así el divino saber y poder, porque ésta es una de las leyes inviolables que tiene puestas en su mundo en todas las cosas que de su jaez y su naturaleza son buenas, puesto que sean temporales y muncho [sic] más en las que dirigen los hombres a la verdadera vida y bondad eternal [...], dice Las Casas, ibid., p. 536.

${ }^{49}$ Ibid., p. 2465.

${ }^{50}$ Marcel Bataillon, Estudios sobre Bartolomé de las Casas, Madrid, Península, 1976, 325 pp., p. 49.

${ }^{51}$ Colón es la gran figura de la Historia de las Indias. Una de sus razones es el carácter ejemplar que adquirió su vida para el proyecto de las Casas. Es el ejemplo de otro hom-
} 
Y desta manera lo provee y ordena Dios con todos los hombres, y por eso todos en no ofendelle debemos estar muy sobre aviso, y deberíamos suplicalle íntimamente que nos dé a cognoscer [sic] por qué pecados contra nos se indigna, porque, cognosciéndolo [sic], sin duda nos enmendaríamos más aína. Pero cuando Dios nos azota y aflige y el por qué no lo sentimos, verdaderamente muncho [sic] mayor y más cierto es nuestro peligro. ${ }^{52}$

Parte de esta reflexión es la "muerte" del clérigo, pero para el mundo, durante diez años, justamente para tomar el hábito dominico: "Y con esto deseemos de tractar [sic] por algunos años - [en] que el clérigo, ya fraile, fray Bartolomé de Las Casas, durmió al parecer- de las cosas del hasta que ocurra el tiempo, si Dios diere vida, que tornemos a su historia, de quien habrá bien que decir." 53 Este acto, más que una mera respuesta a las "amarguras," del fracaso parece poner de manifiesto la idea de un retiro para alcanzar una espiritualidad más honda en el claustro.

Vemos entonces perfilada la imagen de un "hombre de Dios" que deja atrás a la del caballero cristiano y que perfila ya la imagen de profeta que grita, que vocifera, sobre la que ya tanto se ha polemizado. ${ }^{54}$

Es muy importante notar que la autorrepresentación del obispo enfatiza de manera muy nítida el tópico del "justo perseguido," imagen que parece no estar exenta de autoalabanza. Este sentido puede observarse nítidamente cuando enfrenta la oposición a su proyecto de reforma de Indias:

Ésta es averiguada costumbre del mundo y aun regla general que Dios en todo él tiene, o permitida o establecida, conviene a saber: que todos aquellos que pretendan seguir y defender la verdad y la justicia sean desfavorecidos, corridos, perseguidos y mal oídos, y como desvariados y atrevidos y monstruos entre los otros hombres tenidos, mayormente donde interviene pelea de

bre "bueno, pero ciego" que no supo reconocer sus errores ni los castigos que le envió Dios para que cambiara su actitud hacia los indios.

${ }^{52}$ Las Casas, op. cit., p. 939.

${ }^{53}$ Ibid., pp. 2471-2472.

${ }^{54}$ Philippe I. André-Vicent, Bartolomé de las Casas, prophète du Nouveau Monde, París, Librairie Jules Tallandier, 1980, 207 pp. 
arraigados vicios; y la más dura suele ser la que impugna el avaricia y cudicia [sic]; y, sobre todas, la que no puede sufrirse como terribilísima, si se le allega resistencia de tiranía. ${ }^{55}$

Pero aún otra cosa se le estaba aparejando [a Fonseca] mayor por el perseverar en querer abatir al clérigo, por quien parecía que Dios peleaba, como quiera que no pretendiese sino la verdad y justicia y defender que no pereciese la mayor parte del linaje humano. ${ }^{56}$

Esta fue una de las cosas que acaecieron en España: que un clérigo harto pobre y sin renta y persona que le ayudase y ningún favor adquirido por industria humana, sino sólo el que Dios le quiso dar, antes perseguido y abominado en todo el mundo (porque los españoles destas Indias hablan dél como quien, según ellos imaginaban los destruía y con ellos a toda Castilla), hobiese tanto lugar con el rey que se moviese concederle que señalase personas del Consejo, como cuasi jueces sobre el Consejo que también era del rey, y allegase a ser causa de todo lo que está referido y que más se dirá dél. ${ }^{57}$

Finalmente, puede concluirse que la autoescritura en la Historia de las Indias tiene justificación plena en el marco de la historiografía del siglo XVI. Sin embargo, hay que recalcar que el propósito apologético (defensa de la verdad, del honor, de la fama de fray Bartolomé), el ejemplar y de acreditación del autor-narrador mediante la participación testimonial del personaje tensan el texto histórico de ese tiempo hasta el grado de que la proyección de la autoimagen de fray Bartolomé se traduce - casi directamente - en un efecto de subjetividad que choca con el canon histórico, que el fraile trató de evitar. Pero, ante todo, lo que hay que tener muy presente es que esta habilitación del dominico como protagonista se sustenta en la idea de que traza su labor historiográfica desde otro enfoque, con otros valores y que por consiguiente configura de manera diferente la trama y el sentido del acontecer. Desde allí parece ampliamente justificada la pretensión autobiográfica del obispo de Chiapa.

\footnotetext{
${ }^{55}$ Las Casas, op. cit., p. 1772.

${ }^{56}$ Ibid., p. 2373.

${ }^{57}$ Ibid., p. 2365.
} 
Esto no quiere decir que no existan "deslices" de una voz muy personal ${ }^{58}$ (una voz que "clama en el desierto", según palabras de fray Bartolomé) al decir de los historiadores actuales.

Recibido: noviembre de 2006 Aceptado: marzo de 2007

${ }^{58}$ El proyecto de Las Casas fue establecer el estatus único de su voz. Por esta razón muchos de sus escritos son implícita o explícitamente autobiográficos. $C f r$. Anthony Pagden, European encounters with the New World: from Renaissence to romanticism, Yale University Press, New Haven and London, 1993, 289 pp., p. 34. 
